\title{
Effect of MgO to Fatty Acid Molar Ratio on the Production of Magnesium Salt of Fatty Acid from Palm Fatty Acid Distillates (PFAD) for Food Additives
}

\author{
Listianingrum $^{1}$, Reni Yuniarti $^{1}$, Rd.H.R.M.T. Al-Aziz ${ }^{1}$, Defri Rizaldy $^{2}$, Muhamad Insanu ${ }^{2}$, \\ Ardiyan Harimawan ${ }^{1}$, and Dianika Lestari ${ }^{1 *}$ \\ ${ }^{1}$ Institut Teknologi Bandung, Department of Chemical Engineering, 40132 Labtek X Building, Jalan \\ Ganesha 10, Bandung, Indonesia \\ ${ }^{2}$ Institut Teknologi Bandung, School of Pharmacy, 40132 Labtek VII Building, Jalan Ganesha 10, \\ Bandung, Indonesia
}

\begin{abstract}
Palm Fatty Acid Distillate (PFAD), a by-product of CPO industry, contains approx. $82 \%$-wt of free fatty acids, which can be utilized as raw material for Magnesium Salts of Fatty Acids (Mg-PFAD). The objectives of the experiment were to produce Mg-PFAD salts through saponification-fusion reaction of PFAD at low temperature and ambient pressure and investigate the effect of $\mathrm{MgO}$ to fatty acid molar ratio on reaction conversion and yield. Next, washing Mg-PFAD salts with ethanol was able to facilitate the recovery of vitamin E (tocopherol and tocotrienol) from PFAD. Composition of Mg-PFAD were determined by AAS and GC analysis. Based on the data, yield of Mg-PFAD was increased by the increased of $\mathrm{MgO}$ to PFAD molar ratio. Mg-content of the product was within the standard according to FAO reference $(4-5 \%-w t)$. Reaction was completed within 5-7 min after the addition of $\mathrm{H} 2 \mathrm{O}$ (as catalyst).
\end{abstract}

\section{Introduction}

Indonesia is one of the largest Crude Palm Oil (CPO) producers in the world, where the production was reported to reach 33.4 million tons in 2015 [1]. Palm Fatty Acid Distillate (PFAD) is by-product of the CPO refining process from the deodorization unit, with a high fatty acid content of $82 \%$ and is estimated to be about $4 \%-w$ CPO [2]. This fatty acid can be utilized to produce metal salts, such as magnesium stearate, which is abundantly used in food and pharmaceutical industries as emulsifier, lubricants, anti-caking agent. In addition, thermal treatment in deodorization unit will transfer most of vitamin E content from CPO to PFAD. Reduced mass flow and massive stacking of vitamin $\mathrm{E}$ will increase the vitamin $\mathrm{E}$ content in PFAD up to 5 times higher than in CPO, which is about 4000-5000 ppm or about $0.5 \%-\mathrm{w}[3]$. This will increase the feasibility of vitamin E extraction from PFAD.

Metal salts are defined as products of reaction from saturated or unsaturated fatty acid with alkali, alkaline or transition metals. There are various methods usually applied for the commercial manufacture these metallic salts, namely decomposition process, fusion process,

${ }^{*}$ Corresponding Author : dianika@che.itb.ac.id 
and modified reaction process. The fusion reaction was known to have advantages such as the low temperature reaction and atmospheric pressure, fast reaction (3-5 minutes), and the possibility to utilize its exothermic reaction heat [4]. This research aims to investigate the effect of molar ratio between free fatty acid (FFA) in PFAD and $\mathrm{MgO}$ on reaction conversion and its magnesium salts' yield, which are substantial for process optimization at later stages.

\section{Materials and Methods}

This research adapted the method of Rogers patent (1959), US Patent number 2890232 for PFAD [5]. 100 grams of PFAD and 10.6 grams of $\mathrm{MgO}$ was mixed at $80^{\circ} \mathrm{C}$, then 3.2 grams of water was added while maintaining the heating process. The saponification reaction will occur at $98{ }^{\circ} \mathrm{C}$ and completed when the temperature reaches around $105{ }^{\circ} \mathrm{C}$ [6]. The experimental scheme of research is shown in Fig.1. In this experiment, we varied the molar ratio of fatty acids in PFAD to $\mathrm{MgO}$, as shown in Table 1 . Amount of water added as a catalyst was equally set of 3.2 grams in all variations.

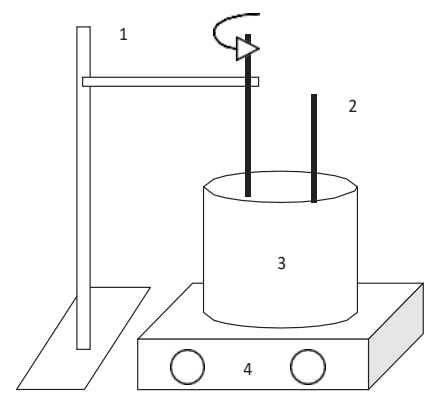

1. Overhead stirrer

2. Thermometer

3. Reactor

4. Heater

Fig. 1. Schematic experiment diagram

Table 1. Variation of molar ratio of fatty acids contained in PFAD and $\mathrm{MgO}$

\begin{tabular}{|c|c|c|}
\hline No. & Molar ratio of fatty acids : MgO & Temperature feeding of MgO \\
\hline 1 & $1.4: 1.00^{*}$ & \\
\hline 2 & $2: 1^{* *}$ & \multirow{2}{*}{$80^{\circ} \mathrm{C}[5]$} \\
\hline 3 & $1: 1.00$ & \\
\hline 5 & $1: 1.25$ & \\
\hline 6 & $1: 1.50$ \\
\hline
\end{tabular}

The flow diagram of experiments is shown in Fig 2. Reaction yield was calculated based on the reaction's mass balance. Atomic Absorption Spectroscopy (AAS) was used to measure Mg content of Mg-PFAD salts and Gas Chromatography - Mass Spectrometry (GC-MS) was used to observe Mg-PFAD salt formed as well as its quantity. The data from GC-MS was showed as percent area detected related to the percent composition of the sample. 


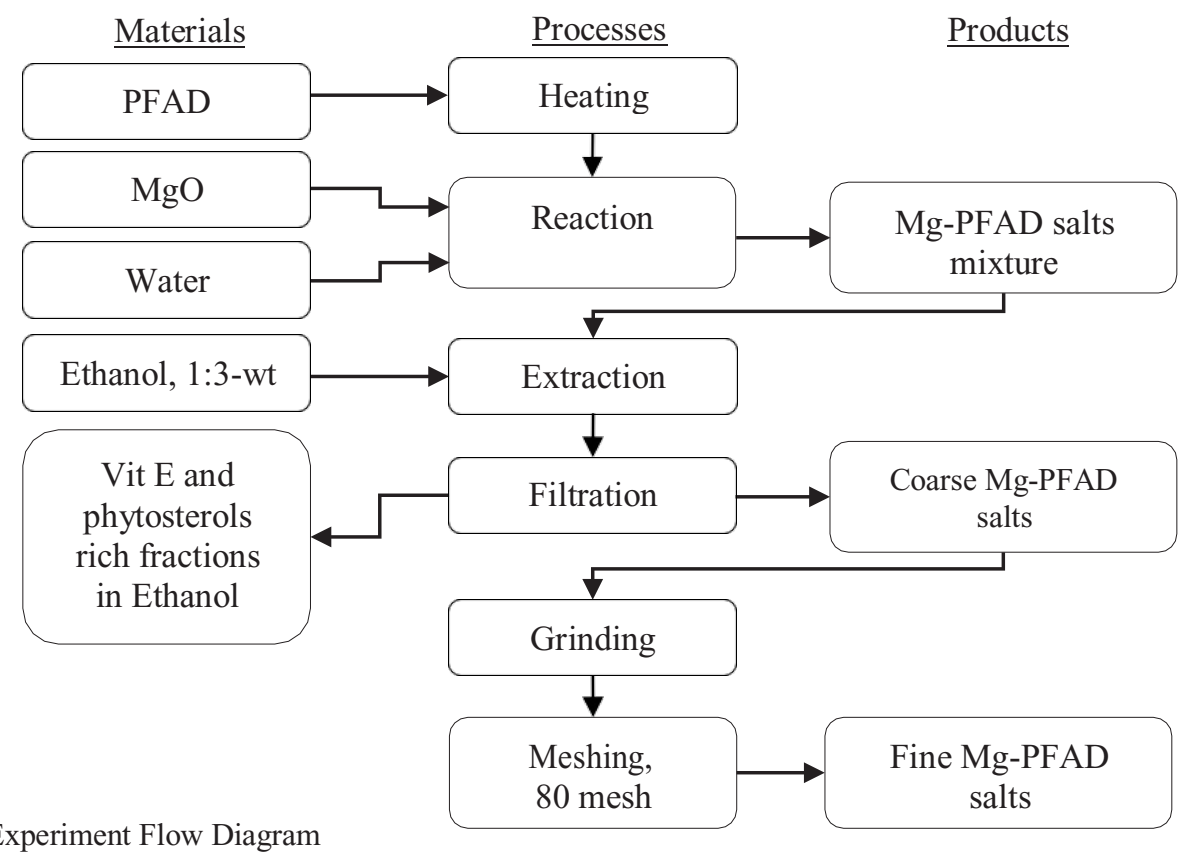

Fig. 2. Experiment Flow Diagram

\section{Results and Discussions}

\subsection{Palm Fatty Acid Distillate Analysis}

Table 2 presents that PFAD used in this experiment has PFAD content of $94.35 \%$, which was obtained from acid value analysis. Later, it was required to determine the conversion of reaction, through Equation 1. Most types of FFA content of PFAD are palmitic and oleic acid by $51.38 \%$ and $39.85 \%$ consecutively.

Table 2. Fatty Acid Composition of PFAD

\begin{tabular}{|l|c|}
\hline & Fatty acid content (\%) \\
\hline PFAD & $94.35 \pm 0.35(\mathrm{AV}=198.2 \mathrm{mg} \mathrm{KOH} / \mathrm{g}$ sample $)$ \\
\hline Palmitic acid & 51.38 \\
\hline Linoleic acid & 4.44 \\
\hline Oleic acid & 39.85 \\
\hline
\end{tabular}

The number of FFA in PFAD obtained from different by-products of CPO processing may vary. FFA composition in PFAD may range from $65.50 \%$ to $95.55 \%$ depends on the quality of purified $\mathrm{CPO}$ and the process condition of rafination. 


\subsection{Effect of FFA to MgO molar ratio on fatty acid conversion and Mg-PFAD salts yield}

Figure 3 shows the effect of FFA to $\mathrm{MgO}$ molar ratio on reaction yield. From this experiment, the reaction yield ranges from $88-92 \%$ for FFA to $\mathrm{MgO}$ molar ratio of 1:1 to 1:1.5.

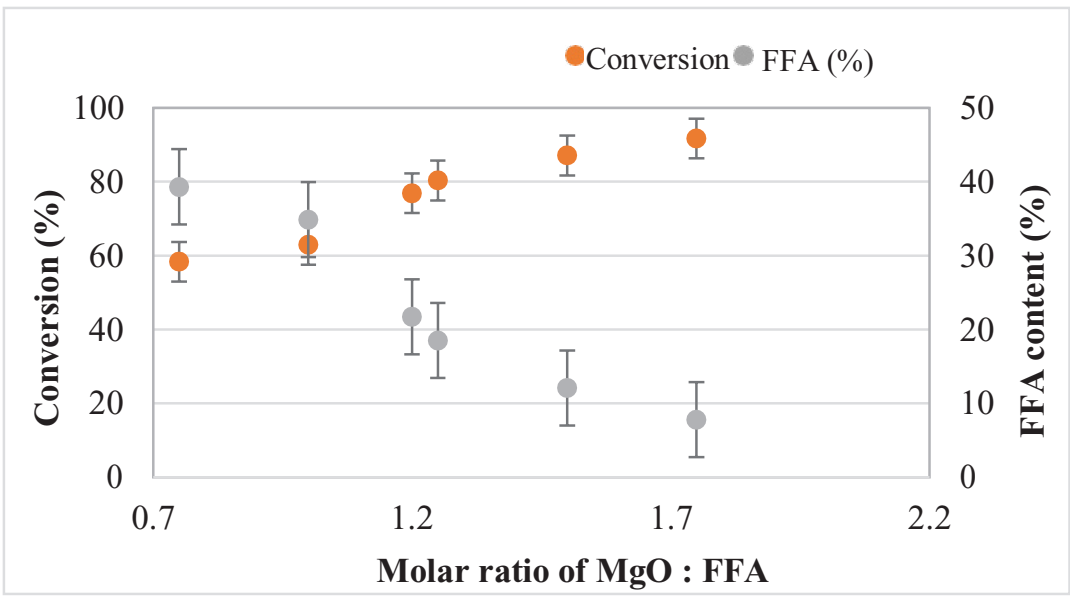

Fig. 3 Profile of reaction conversion and FFA percentage on different MgO to FFA molar ratio

Based on the results of the experiment (Fig.3), it was conducted an analysis of factorial design of percent reaction conversion against the ratio of moles of $\mathrm{MgO}$ to PFAD. Based on the analysis of the data, the molar ratio of feed (A) greatly affects the conversion of reaction (with a P-value of 0.000 ), whereas the initial temperature of the reaction (B) and the interaction between the $\mathrm{A} \& \mathrm{~B}$ has no effect against a conversion reaction (with $\mathrm{P}$-value 0.931 and 0.961 ). The largest conversion obtained by conducting molar ratio of $\mathrm{MgO}:$ FFA as 1:1.75, when $\mathrm{MgO}$ molar ratio excess of stoichiometric requirement. Excess $\mathrm{MgO}$ suspected to drive the reaction to the right (product side) so that the magnesium salts products increased and thus reduced the levels of FFA content in the product. It can be seen that the more the $\mathrm{MgO}$ fed, then the lower the conversion reaction. However, the conversion of $91.75 \%$ did not meet the standard commercial magnesium stearate product because it still has FFA of 7.79\%. Based on Ph Eur 8th Ed 2014, magnesium stearate must meet the limits of maximum FFA content by $4 \%$ or less [7]. Therefore, further processing is required to reduce the content of FFA in the final product.

$$
\mathrm{MgO}_{(\mathrm{s})}+2 \mathrm{RCOOH}_{(\mathrm{l})} \rightarrow \mathrm{Mg}(\mathrm{OOCR})_{2(\mathrm{~s})}+\mathrm{H}_{2} \mathrm{O}_{(\mathrm{l})}
$$

\subsection{Effect of FFA to MgO molar ratio on Mg-PFAD salts composition}

Mg-PFAD salt composition represents characteristic of the salt and determines its properties and functionality. Fatty acid composition in Mg-PFAD salts showed similar composition to fatty acid composition on PFAD (Fig. 4). Briefly, PFAD is composed by low content of stearic acid (C18:0) (4-5\%) and higher content of palmitic acid (C16:0), oleic acid (C18:1), linoleic acid (C18:2) and linolenic acid (C18:3) [8]. Furthermore, the result showed that FFA to $\mathrm{MgO}$ molar ratio had no significant effect on $\mathrm{Mg}$-PFAD salts composition. 


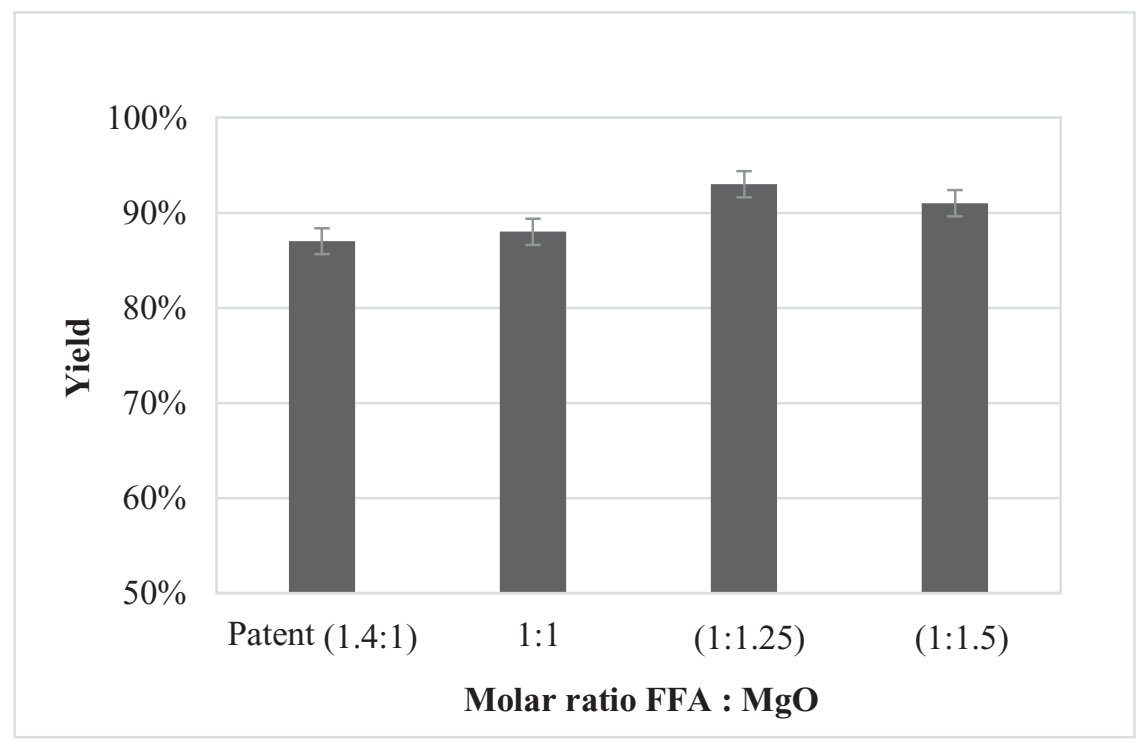

Fig. 4. Reaction yield on different FFA to $\mathrm{MgO}$ molar ratio

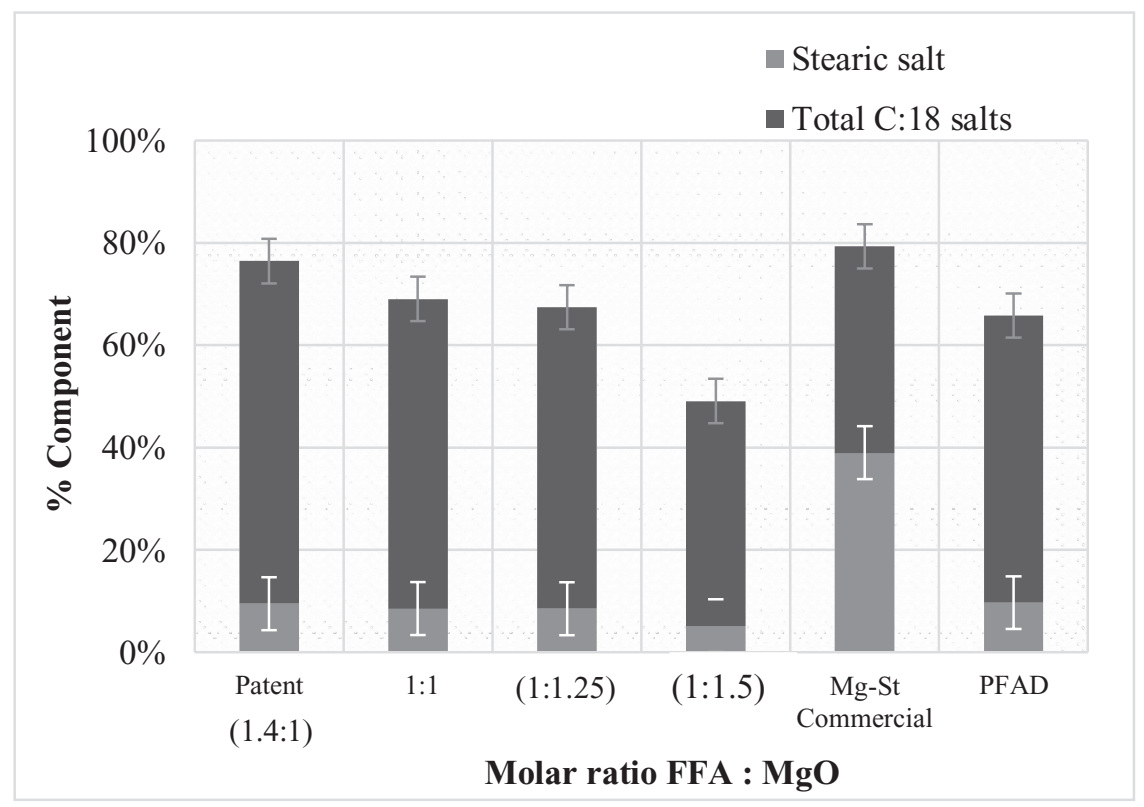

Fig. 5. Mg-PFAD salts composition on different FFA to $\mathrm{MgO}$ molar ratio 


\subsection{Effect of FFA to MgO molar ratio on Mg content of Mg-PFAD salts}

Fig. 6 shows magnesium content in Mg-PFAD salts on different FFA to $\mathrm{MgO}$ molar ratio. Based on this result, FFA to $\mathrm{MgO}$ molar ratio showed no significant effect on $\mathrm{Mg}$ content of Mg-PFAD salts.

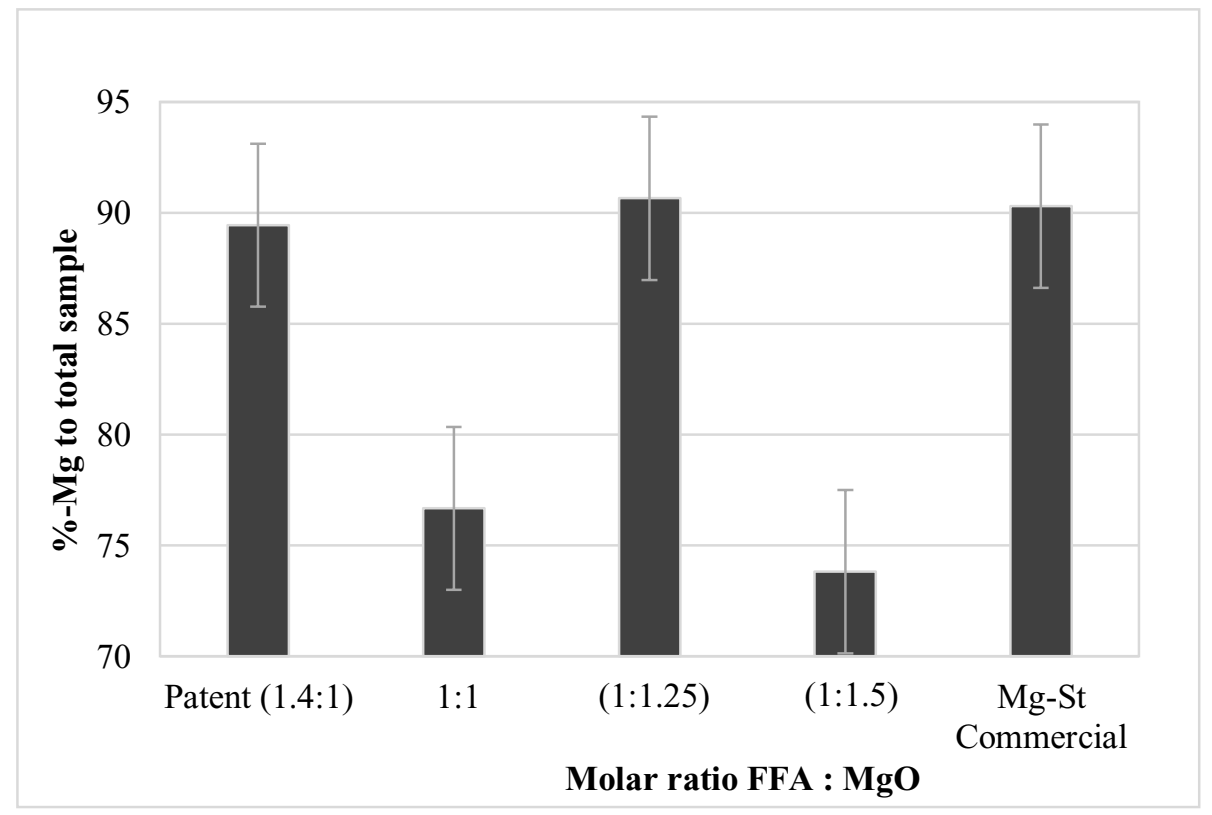

Fig. 6. $\mathrm{Mg}$ content in Mg-PFAD salts on different FFA to $\mathrm{MgO}$ molar ratio

\section{Conclusions}

Based on the experimental data, we conclude that fatty acid to $\mathrm{MgO}$ molar ratio affect reaction yield and composition of $\mathrm{Mg}$-PFAD salts. Mg-content of the product was within the standard according to FAO reference (4-5\%-wt). Reaction was completed within 5-7 min after the addition of $\mathrm{H} 2 \mathrm{O}$ (as catalyst).

This research was funded by Grant Research Sawit (GRS, K-16) Programme from BPDPKS, Indonesian Ministry of Finance, 2016

\section{References}

1. Indonesian Palm Oil Producers Association and Indonesian Ministry of Agriculture, (2016).

2. A.G.M. Top, Lipid Tech, 22, 11-13 (2010)

3. Y. Basiron, B.S. Jalani, K.W. Chan, Malaysian Palm Oil Board, 2 (2000)

4. Manufacture of Metal Soaps, US2890232 (1959)

5. J.D. Opem, R.H. Rogers, US2890232 (1959)

6. R.H. Rogers, P. Park, J.D. Opem, US3047496 (1962)

7. Ph. Eur, 8 (2014)

8. Maarasyid, Cici, I.I. Muhamad, E. Supriyanto, Teknologi 69, 4 (2014) 